\title{
Empresarialidad e instituciones: dos nuevas perspectivas del análisis regional contemporáneo
}

\begin{abstract}
This paper offers a review of the main progress made in entrepreneurship analysis and institutional economics, discussing its possible integration to general theory of economic development, considering the increasing importance that these topics have gained in contemporary approaches of terriorial development.

Keywords: Entrepreneurship, institutions, regional economic development.

\section{Resumen}

El objetivo de este artículo es realizar un repaso de los principales avances en el análisis de la empresarialidad y de la economía institucional, discutiendo su integración a la teoría general del desarrollo económico a partir de la constatación de la centralidad que estos temas han adquirido en los enfoques contemporáneos del desarrollo territorial.
\end{abstract}

Palabras clave: empresarialidad, instituciones, desarrollo económico regional 


\section{Introducción}

U n aspecto central de las aproximaciones estructuralistas y keynesianas del desarrolo económico es que sus interpretaciones implícitamente suponían que no se presentaban restricciones en el lado de la oferta. Los agentes entonces reaccionarían (instantáneamente o con demoras) a ciertos incentivos de demanda. Enunciado así, el problema del desarrollo se remitía a las fuentes que generaban o disolvían dichos incentivos. Inicialmente, no se preveía que el estudio de las características específicas que pudieran asumir dichas reacciones (decisiones de inversión, en esencia) podría mejorar la comprensión del proceso. Si bien existían varias interpretaciones sobre los factores que jugaban en la aparición y consolidación de los estímulos de demanda, casi no había disenso acerca de qué ocurriría después de que éstos se hiciesen presentes.

Esto no significa que las teorías del desarrollo dominantes en los ' 60 y '70 hayan ignorado las limitaciones que la (escasez de) empresarialidad puede imponer al proceso de desarrollo. Hirschman (1958) se refería a los límites en la capacidad de movilización y organización de recursos como factor limitante del desarrollo, acordando que la actividad empresarial contiene parte de esta capacidad, pero esta misma también puede revelarse en el sector público ${ }^{1}$. Por este motivo, la escasez de talento empresarial en el sector privado no representaba, para las teorías del desarrollo vigentes durante la posguerra, una barrera, en la medida en que esta tarea pudiese ser asumida por el Estado. Esta misma hipótesis es abonada por Leff (1979), al observar que la política de compras del sector público de los países en desarrollo ha oficiado frecuentemente como complemento de las restricciones en el sector

\footnotetext{
* Becaria del CONICET, Docente del Departamento de Economía de la Universidad Nacional del Sur, Argentina. E-mail: vviego@criba.edu.ar

** Recibido el 13 de mayo de 2003, aprobado el 30 de diciembre de 2003.

${ }^{1}$ Se debe aclarar, sin embargo, que en contribuciones posteriores, Hirschman destaca la importancia del estudio de las estrategias de los actores y la necesidad de analizar las relaciones contradictorias entre los agentes involucrados en una trama productiva, en particular las conductas de "voice, exit and loyalty" (Hirshman, 1970).
}

privado. Así, los autores inscriptos en esta visión no consideraban problemas de elasticidad en el lado de la oferta una vez generado el mercado. En presencia de condiciones de demanda (creadas por el Estado en situaciones de subdesarrollo) que generasen estímulos suficientes para agregar nuevas inversiones, se suponía que los empresarios potenciales reaccionarían consecuentemente.

Hasta los '70, el enfoque estructural prevalecía también en otros campos de la ciencia económica. En la organización industrial, por ejemplo, el enfoque dominante se basaba en el paradigma "estructura-conducta-desempeño", de tradición neoclásica ${ }^{2}$. En esencia, este esquema postula que la conducta de una firma individual se encuentra fuertemente condicionada por las características estructurales del mercado (economías de escala, concentración de la oferta, barreras a la entrada). En el plano regional, las interpretaciones vigentes en los '50 y '60 reflejan el mismo razonamiento que el prevaleciente en la organización industrial. La estructura intra e inter-regional (en términos de nivel de industrialización y de las formas de inserción de las regiones en los esquemas de intercambio) juega, para países y regiones, el mismo rol que la estructura de mercado tiene sobre la conducta de las firmas.

Así, las condiciones estructurales constituyen uno de los ejes analíticos centrales en los enfoques que predominaron en diversas disciplinas económicas hasta los '70. Al mismo tiempo han sido uno de los principales puntos de disenso con las nuevas corrientes. La diversidad de desempeños observados entre regiones (y entre firmas), aun en un mismo contexto, alentó la búsqueda de factores explicativos adicionales que captaran la incidencia

\footnotetext{
${ }^{2}$ Se debe señalar, sin embargo, la diferente visión de los enfoques estructurales en la disciplina del desarrollo económico de los pertenecientes a la organización industrial. El carácter "estructural" de las interpretaciones respondía para los primeros a concepciones dependentistas e incluso marxistas del desarrollo económico, mientras que para los segundos era el mercado quien imprimía la naturaleza estructural de las conductas y resultados de las empresas. Otra diferencia radica en la perspectiva global de los primeros, en contraposición a la microeconómica del enfoque estructuraconducta-desempeño. Lo común entre ambas interpretaciones sea tal vez la naturaleza poco cambiante de la estructura, más allá de su origen (social, mercado).
} 
de elementos idiosincrásicos individuales. Es así como la empresarialidad es incorporada a la teoría del desarrollo, incluso desde una perspectiva regional. Adicionalmente, el proceso de reestructuración industrial y del Estado que tuvo lugar en varias economías a partir de los '70 configuró un escenario propicio para la reapertura del debate sobre el "lado de la oferta” en la mecánica del desarrollo.

Este apartado se ocupa de repasar los principales puntos de la discusión sobre la relación entre empresarialidad y desarrollo. En la sección siguiente se exponen los fundamentos de la introducción de este nuevo elemento en el análisis y una breve mención del contexto histórico que dio pie a su emergencia. En el apartado tres se presentan de un modo esquemático los principales factores que, según la literatura, inciden en la empresarialidad. En el cuatro se ofrece un repaso de cómo la ciencia regional ha incorporado esta discusión en los análisis de desarrollo local. Finalmente, se presenta una breve síntesis.

\section{La rejerarquización de la empresarialidad}

En esencia, es posible distinguir tres factores que sustentan la rejerarquización del empresario en las discusiones sobre desarrollo económico: dos relacionados con la teoría y uno vinculado al contexto histórico.

El primer factor está vinculado al viraje teórico experimentado a fines de los ' 70 , que ahora pone el acento en las conductas de los agentes, y por ende, desplazó las interpretaciones macro-estructurales prevalecientes durante los ' 50 y ' 60 . El desarrollo ya no se plantea únicamente en términos de la presencia o ausencia de ciertas actividades motrices, sino también de las particularidades de su comportamiento. Paulatinamente, se fue abandonando la idea de que el perfil sectorial y la magnitud de la inversión constituían la clave del efecto propulsor, para dar pie a consideraciones acerca del dinamismo de las organizaciones involucradas en términos de conductas.

Esta reorientación acompañó la evolución experimentada también por los estudios de organización industrial. Durante los ' 80 , los trabajos de Nelson y Winter (1982) y Nelson (1991) mostra- ron que, aun dentro de una misma rama manufacturera, la conducta de las firmas podía variar ampliamente, revelando la existencia de cierto margen de acción individual, y por lo tanto, de independencia respecto de los condicionamientos derivados de la estructura del mercado ${ }^{3}$. La heterogeneidad interfirma fue interpretada por las nuevas aproximaciones teóricas como signo de que la estructura no cierra por completo la posibilidad de comportamientos discrecionales por parte de las empresas. Derivado de lo anterior, limitar el análisis a cuestiones sectoriales resultaría entonces incompleto. De este modo, para la nueva economía industrial, la conducta relativamente autónoma- de las firmas puede influir significativamente en su desempeño. Esta misma hipótesis parece prevalecer ahora en el análisis del desarrollo regional (Granovetter, 1985; Maskell, 1999).

Por su parte, el creciente reconocimiento de que la estructura (de mercado y del comercio inter-regional) no consigue explicar por completo las diferencias en el desempeño de firmas, regiones y países, permitió la apertura de varias líneas de investigación, ocupadas en identificar elementos adicionales que permitieran una comprensión más integral de estas cuestiones. Una de ellas se enmarca en el estudio de la empresarialidad.

Además de constituir un aporte para la comprensión de la heterogeneidad, la jerarquización de la empresarialidad que tuvo lugar en los '70 se basó en el rol que a este elemento ya se le reconocía en el proceso de desarrollo. Aunque las funciones que la figura del empresario desempeña en dicho proceso parecen evidentes, su estudio fue objeto de obras centrales del pensamiento económico. En las visiones de Kirzner (1973) y Knight (1921), por ejemplo, el empresario tiene a su cargo ciertas tareas que

\footnotetext{
${ }^{3}$ Esta misma apreciación había sido sugerida tempranamente por Florence $(1953 ; 1964)$, que difundió la visión de que las diversidades organizacionales explican una porción significativa de la productividad. En su interpretación, existen elementos más relevantes que la tecnología (determinante en la visión neoclásica de los rendimientos a escala, y por ende, de la productividad) como la organización de las actividades dentro de la planta, el tipo de insumos utilizados y el tipo de mercado abastecido. Con todo, estos aportes sólo fueron incorporados de un modo más sistemático en los análisis de economía industrial y regional a principios de los ' 80 .
} 
resultan básicas en un sistema capitalista, como son la detección de oportunidades de beneficio y la asunción de riesgos derivada de las acciones necesarias para explotarlas. La estrecha vinculación entre empresarialidad y desarrollo también se hace presente en la obra de Schumpeter (1912; 1942), para quien dicho proceso avanza con la aparición de "nuevas combinaciones" (de medios de producción, de bienes, de fuentes de abastecimiento, de mercados, de formas de organización, etc.). Es claro entonces que para esta visión, la mayoría de las instancias de dicho proceso estén motorizadas por la presencia de emprendedores. Para algunos autores, como Harbison (1956) o Leibenstein $(1966 ; 1968)$ el rol del empresario es crítico aun en fases de subdesarrollo, debido a que sobre él recae la tarea de superar las deficiencias típicas de este tipo de economías (mercados incompletos, ambigüedades en la especificación de la función de producción, transabilidad imperfecta de algunos insumos y factores, etc.).

Por último, las transformaciones que han experimentado tanto la teoría como las políticas en esta disciplina, responden también a algunas limitaciones observadas hacia principios de los '70 en el plano de la acumulación (crisis del fordismo) y de la regulación (cuestionamiento del Estado de Bienestar). Por este motivo, desde fines de los ' 70 , el estudio de la actividad empresaria ha concentrado un interés creciente también entre los decisores de política. El retiro progresivo del Estado en áreas de producción y provisión de servicios públicos, la tendencia generalizada a la desregulación de los mercados y los altos índices de desempleo provocados por la reestructuración de las grandes plantas han impulsado la creencia de que la salida de la crisis de crecimiento podría estar basada en una revitalización de la actividad independiente (Subbarao et al., 1995; ILO, 1995). En este nuevo escenario, como la tracción de los grandes establecimientos manufactureros o la participación del Estado en la actividad productiva estarían en principio ausentes, se preveía que los eventuales déficit de empresarialidad representasen ahora un cuello de botella para el desarrollo económico. Por otra parte, la empresarialidad comenzó a ser vista no sólo como factor dinamizante, sino también como mecanismo de creación de empleo, en un contexto en el que las nuevas formas de organización de la producción impulsan fuertes desplazamientos laborales (OCDE, 1998a).
Recientemente se han difundido varios trabajos promoviendo los supuestos "beneficios sociales" de la empresarialidad adicionales a la atenuación de la caída del empleo industrial, como el alejamiento de situaciones de pobreza, los efectos "demostración" sobre el entorno del empresario o la generalización de actitudes "activas" por parte de la comunidad en las regiones atrasadas (OCDE, 1998a; Audrestch $e t$ al., 2002). El pasaje de un empleo en relación de dependencia a la actividad independiente aumenta, para esta nueva concepción, los incentivos para comprometerse en la búsqueda de soluciones y aleja los roles que limitan al individuo a la simple ejecución de rutinas. Así, la empresarialidad es vista como parte de una alternativa que intenta reconciliar el crecimiento económico con la cohesión social (Alburquerque, 1999). Esta nueva orientación también impacta sobre el costo fiscal, debido a que el impulso de la empresarialidad requiere menos fondos que subsidiar industrias en retroceso o una masa creciente de desempleados (OCDE, 1998a).

\section{Factores que inciden en la empresarialidad}

Siguiendo a Malicia y Feser (1999), las teorías de la empresarialidad resultaron una pieza analítica central en el paso de una concepción de desarrollo ligada esencialmente a la industrialización a otra fundada en la innovación. La obra de Schumpeter, en particular, representa el origen de este punto de convergencia. Sin embargo, las relaciones originalmente propuestas giraban en torno a una perspectiva esencialmente macro, sin abordar en detalle los aspectos microeconómicos subyacentes. Es este último aspecto el que distingue una línea de investigación posterior, iniciada a partir de la segunda posguerra. Menos preocupados por la función social y económica del empresario, este grupo de aproximaciones se propone identificar las condiciones materiales e institucionales que impulsan el espíritu empresarial.

El punto de partida de las distintas aproximaciones es el reconocimiento de que la conducta (individual o colectiva) se encuentra en el centro del proceso de desarrollo. En otras palabras, son los agentes (a través de sus acciones) los que hacen que el desarrollo ocurra. Más allá de este rasgo general, los 
enfoques difieren respecto del contenido concreto del término "actividad empresarial" (Soltow, 1968; Baumol, 1968). El progreso hacia un tronco teórico unificado en esta materia se ha visto obstaculizado por la multiplicidad de facetas que convergen en la figura del empresario (innovación, riesgo, etc.) y la existencia de aspectos latentes que parecen trascender la esfera económica. Por este motivo, la empresarialidad se ha convertido en un fenómeno de muy difícil tratamiento tanto desde el punto de vista teórico (trabas para la simplificación y generalización) como empírico (preponderancia de elementos no observables). La diversidad de tratamientos no proviene solamente de diferentes énfasis interpretativos, sino también de que el estudio de esta temática ha sido encarado por distintas disciplinas (psicología, economía, sociología, antropología, historia, etc.), que a su vez se han acoplado con distinto ritmo e intensidad a las explicaciones dominantes en los programas de investigación ${ }^{4}$. No obstante, su inclusión en el análisis resulta ineludible, debido a que -si bien no se conoce con precisión el mecanismo subyacente- cumple un rol fundamental en el desarrollo económico.

Conviene aclarar, antes de este repaso, que la falta de un cuerpo teórico robusto y aceptado en esta problemática hace que la presentación ofrecida aquí sólo aspire a proponer un agrupamiento tentativo de los distintos factores que han sido señalados como influyentes en la empresarialidad ${ }^{5}$.

En principio, es posible clasificar a los determinantes de la empresarialidad en dos grupos. Por un lado, aquellos que describen las condiciones básicas para ingresar $\mathrm{y}$ prosperar en la actividad independiente (requisitos mínimos sin los cuales no habría incentivos para operar una firma), y, por otro, aquellos factores de carácter estructural que subyacen de un modo más o menos permanente en el perfil empresarial de una región o país. En la medida en

\footnotetext{
${ }^{4}$ A pesar de la ausencia de una explicación más integral de los factores que inciden en la empresarialidad, estos enfoques han concentrado la atención por parte de los decisores de política, debido a que -como se verá más adelante- de ellos se derivan implicancias directas para promover la actividad empresarial (Malicia \& Feser, 1999).

${ }^{5}$ La sinopsis presentada de ningún modo constituye el primer esfuerzo en esta materia. O'Kean (2000) y Verheul et al. (2001) ofrecen revisiones alternativas.
}

que los primeros se enfocan en los factores constitutivos más elementales (y que-por ello mismo-no pueden ser desglosados de la propia definición de empresarialidad), estos elementos son considerados aquí como "triviales". A su vez, la intensidad y la naturaleza del fenómeno de la empresarialidad se encuentran condicionadas por un segundo grupo de factores conformado esencialmente por las características del entorno institucional, ya que es allí donde los agentes se abastecen de motivaciones y recursos y donde despliegan sus acciones.

\subsection{Determinantes triviales}

\subsubsection{Motivación}

Una parte sustancial del estudio del perfil de los empresarios se apoya en los objetivos que subyacen en su conducta. En la teoría microeconómica, el supuesto adoptado sobre los objetivos de los agentes constituye una pieza central en la especificación y resultados de la mayoría de los modelos. En particular, varios enfoques de la teoría de la firma consideran a la maximización de beneficios como el único móvil de la acción empresarial. Este supuesto asegura que: (a) la conducta de las firmas esté completamente enfocada a la acumulación de capital; y (b) la inversión esté gobernada por las oportunidades de beneficio. En otros términos, la búsqueda de mayores ganancias y las oportunidades de realizarlas constituyen, para la teoría tradicional, los factores que definen el sendero de expansión capitalista de un determinado país o territorio. El examen de aspiraciones distintas de las vinculadas al beneficio es irrelevante para los neoclásicos, dado que el mercado "penalizaría” las conductas originadas en metas distintas del (máximo) beneficio. Este análisis resulta intrascendente incluso para la visión marxista, debido a que el proceso de acumulación no es concebido como un fenómeno individual, sino esencialmente social.

Este esquema de razonamiento ha recibido varias objeciones, entre ellas las siguientes:

algunos autores (Singh Laumas, 1962; Easterbrook, 1949; North, 1990) han señalado la existencia de factores que condicionan la reacción de los empresarios a las oportunidades de beneficio. En particular, la corriente 
neo-institucionalista sostiene que los talentos empresariales varían de acuerdo a las características institucionales del ambiente en el que operan. En otras palabras: no existe una oferta ilimitada de empresarios para cada nivel de oportunidades de beneficio. Para esta escuela, en algunos ambientes las oportunidades pueden verse "empañadas" por determinadas condiciones fuera de la esfera económica (culturales, sociales, regulatorias, etc.) que limitan la capacidad de respuesta de la inversión. Si bien esta cuestión es el eje central del inciso que sigue, basta recordar, por el momento, que la existencia de oportunidades de beneficio y una motivación favorable de los empresarios no aseguran la acumulación de capital.

- Varios trabajos sugieren que el beneficio no constituye el único factor motivacional que impulsa el desarrollo capitalista. Desde la psicología, varios investigadores han intentado identificar algunos rasgos que intervienen en la definición del perfil empresarial de los individuos ${ }^{6}$. La tesis sostenida por McClelland a principios de los ' 60 es que los empresarios están motivados por la "necesidad de logro" (Freeman, 1976; Tekiner, 1980). Según este autor, la compensación monetaria sólo operaría como un factor secundario ante la necesidad de realización. En la misma línea, otros autores (Wilken, 1979, citado por $\mathrm{O}^{\prime}$ Kean, 2000) identifican un conjunto de atributos de la personalidad, como la necesidad de reconocimiento social, poder, prestigio, etc., que resultan igualmente compatibles con la acumulación de capital. Estas metas se manifestarían en ciertas actitudes (atracción por las actividades que requieren habilidades, iniciativa, conducta exploratoria, interés por corregir fracasos, etc.) que se asemejan a los rasgos del emprendedor (asunción de riesgo en función de la habilidad y no de las oportunidades, necesidad de conocer resultados de sus decisiones, anticipación al

${ }^{6}$ Cabe aclarar que estos trabajos utilizan una definición amplia de emprendedor, distinta de la considerada por la teoría económica. Mientras que para esta última la empresarialidad está asociada a ciertas funciones limitadas a la esfera privada, para los primeros puede emerger en el ámbito público o privado (Tekiner, 1980). futuro, etc.). La diferencia entre la concepción más tradicional del empresario y la propuesta por los enfoques psicológicos es que el primero reacciona sólo ante los incentivos de mercado para maximizar ganancias, mientras que el último pone el énfasis en la búsqueda de oportunidades para ejercitar sus talentos o lograr el reconocimiento de algunos segmentos de la sociedad (Kunkel, 1963; 1971). Implícitamente, los análisis que adhieren a esta visión suponen que, superadas las restricciones motivacionales, no deberían existir otros obstáculos para la inversión ${ }^{7}$.

Otro grupo más heterogéneo de trabajos postula que la búsqueda de beneficios, de poder, de prestigio o la necesidad de logro no agotan el abanico de objetivos empresariales. Elementos como la estabilidad, la necesidad de independencia o la salida del desempleo forman parte de las metas de algunos empresarios. Estos fines no necesariamente aseguran la expansión de la firma, y por ende, introducen mayores restricciones a la correspondencia entre oportunidades y decisiones de inversión planteada inicialmente (Garnsey, 1996; Bhide, 1996). El aporte más significativo en esta línea sea tal vez el de Baumol (1990), quien reconoce que la oferta de empresarios no es el punto central para el desarrollo, sino su orientación (productiva, rentista, etc.). Y ello depende, en gran medi$\mathrm{da}$, de los retornos que la sociedad genera para cada orientación.

- Por último, una línea de investigación recientemente abierta en la teoría del crecimiento de

${ }^{7}$ Este tipo de abordaje ha recibido numerosas críticas. Una de las debilidades analíticas observadas es suponer que los capitalistas tienen una fuerte inclinación hacia la acumulación de capital, que podría resultar independiente de la tasa de retorno (Greenfield \& Strickon, 1981). Otra de las limitaciones radica precisamente en la amplitud con que se define la figura del emprendedor. Una actitud de búsqueda continua por parte de los individuos es común de encontrar en los cuadros empresariales, pero no es una característica exclusiva de este segmento ocupacional. Los mismos rasgos pueden ser observados en artistas, científicos, inventores, etc., y estas ocupaciones difícilmente pueden ser consideradas como constitutivas de la empresarialidad (Garnsey, 1988). 
la firma advierte que las metas empresariales pueden variar de acuerdo al ciclo de vida de la organización (Greiner, 1974; Garnsey, 1996; Alstrom, 1998). En la medida en que cada fase del ciclo vital de una empresa presente nuevos problemas, los objetivos y acciones orientadas a conseguirlos variarán en el tiempo. De este modo, mientras que las firmas en sus inicios buscan en su mayoría la estabilización del flujo de caja, las de mayor edad aspiran a consolidar la cartera de clientes. En este proceso es posible que la obtención de mayores ganancias se convierta en el foco de las acciones recién en períodos avanzados del ciclo de vida.

Como emerge de los puntos anteriores, diversas disciplinas han intentado especificar los factores que influyen en la motivación, con el objeto de ampliar la comprensión de los móviles que determinan la conducta empresarial y enriquecer o refutar la hipótesis de maximización de beneficios. De sus aportes se deriva entonces que los objetivos empresariales pueden diferir de una firma a otra, y aun en una misma organización a lo largo del tiempo. Sin embargo, conviene tener presente que si bien las aspiraciones al momento de puesta en marcha de la actividad pueden ser diferentes de aquellas prevalecientes en períodos posteriores, no necesariamente implica que no estén relacionadas. En el caso extremo de la firma capitalista "ideal", el objetivo de acumulación puede estar subyacente en la mayoría de las metas de corto plazo de la organización. En este caso, las metas intertemporales coinciden. En muchas ocasiones, por el contrario, el motivo que origina el inicio de una actividad independiente es modesto (generalmente vinculado a restricciones de acceso o de reincorporación al sector asalariado del mercado de trabajo, fenómenos de discriminación social, etc.). La naturaleza del objetivo subyacente en la creación (es decir, si el negocio buscado es o no el de máximo beneficio posible) podría estar reflejando un estilo de comportamiento que, de no evolucionar en el futuro, impondrá su sello sobre las decisiones posteriores que tome la empresa. Esto es, que una decisión inicial poco ambiciosa probablemente sea seguida por un patrón de comportamiento de similares características.

Para concluir, las aspiraciones personales de aquellos que llevan adelante una firma se han convertido en un elemento central en la discusión sobre empresarialidad. Si bien no hay acuerdo en la literatura acerca del peso relativo de los factores subyacentes (psicológicos, culturales, económicos) en la formación de los objetivos empresariales, no hay duda de que el dinamismo de las conductas de las firmas está estrechamente vinculado con las aspiraciones de sus empresarios acerca del negocio. En la medida en que las acciones de las empresas influyen sobre el sendero evolutivo del sistema productivo, el análisis de la motivación resultará relevante también en la esfera del desarrollo económico.

\subsubsection{Acceso a los recursos y capacidades}

Una línea de investigación recientemente abierta en la organización industrial enfatiza el rol de las capacidades en el proceso de crecimiento (Teece $\&$ Pisano, 1994; Langlois, 1998; Langlois \& Foss, 1999). Según esta vertiente, la "generosidad" del ambiente (oportunidades) o las preferencias individuales no son suficientes para lograr que un individuo con inclinación hacia los negocios concrete sus aspiraciones. Es preciso tener en cuenta la capacidad de los agentes para movilizar los recursos necesarios para poner en marcha y llevar adelante un proyecto empresarial. En este caso, los recursos están conformados tanto por factores de producción e insumos como por el stock de conocimientos necesarios para operar en el mercado. Brevemente, este enfoque revisa las competencias acumuladas en el empresario (antecedentes, formación, entrenamiento) y aquellas generadas en la propia organización (aprendizaje, etc.).

A nivel micro, los factores que definen el nivel de acceso a los recursos son de carácter endógeno y exógeno a los individuos. Los primeros se centran exclusivamente en la aptitud de los agentes para concebir, diseñar, organizar y financiar una idea de negocio. En particular, el acceso al conocimiento para una actividad dada depende del nivel de formación escolar y de la experiencia del individuo y de su talento innato para almacenar y aplicar conocimientos. Por su parte, el acceso a los recursos materiales depende de la posesión de activos monetarios con los cuales reunir la dotación de maquinarias, instalaciones y personal que materialice el proyecto. Ambos aspectos están asociados, con frecuencia, al grupo social al que pertenece el individuo; la perte- 
nencia a un hogar de ingresos altos o con tradición empresarial puede fomentar la empresarialidad al allanar el acceso a los recursos ${ }^{8}$. En conjunto estos elementos forman parte de los factores endógenos al individuo (Storey, 1994a; Verheul et al., 2001). Los exógenos, en cambio, aluden a aquellas condiciones del ambiente que animan u obstaculizan tanto la adquisición de conocimientos como de los medios de producción. En referencia al conocimiento, se considera que los sistemas educativos con acceso restringido, las leyes de protección a los inventos y descubrimientos o los canales arancelados de circulación de información, entre otros, ponen barreras de acceso, y por ende, limitan su acumulación a nivel individual. Con relación a los factores de producción, una cuestión central es el grado de segmentación de la oferta de créditos en el mercado de capitales (Greenwald \& Stiglitz, 1990; Storey, 1994b; Binks \& Ennew, 1997) ${ }^{9}$.

En términos agregados, la aplicación de este enfoque consiste en considerar la cantidad de individuos con perfil satisfactorio en términos de capacidades para la actividad empresarial como una magnitud que se ve influida por las características demográficas y económicas de la población. Entre los factores más citados se mencionan:

\section{- la densidad poblacional y tasa de urbanización. \\ Se supone que las áreas urbanas y/o con alta densidad de población, en la medida en que concentran la oferta de servicios educativos y de información, contienen también una mayor proporción de individuos potencialmente ca- pacitados para gestionar una firma.}

- La tasa de escolaridad. Si bien no hay acuerdo acerca de cuál nivel de educación formal es el que influye sobre la empresarialidad ${ }^{10}$, hay consenso en que esta última aumenta con el nivel de escolaridad de la población.

\footnotetext{
${ }^{8}$ Este argumento se contrapone a la hipótesis del desplazamiento enfocada en los grupos étnicos, que sostiene que el sentimiento de discriminación impulsa la actividad empresarial. Los principales argumentos de esa visión alternativa se exponen más adelante.

${ }^{9}$ Dificultades exógenas de acceso a los recursos dependen también de las características de la actividad en la que se desenvuelve o desea ingresar el emprendedor. Esto será tratado con más detalle en el siguiente inciso.
}

La disponibilidad de información. Se refiere a las fuentes a las que el individuo puede acudir para adquirir o complementar los conocimientos transmitidos por las organizaciones escolares formales. Se incluyen en este rubro la dotación de centros de capacitación y extensión que ofrecen información y asesoramiento técnico para instalar una firma o introducir mejoras en las ya existentes (Sweeney, 1987).

La estructura productiva. La presencia de empresas pequeñas en la estructura productiva cumple un rol difusor de conocimientos. Ello se debe a que este tipo de organizaciones opera con tecnologías que, por un lado, facilitan la acumulación de conocimientos específicos por parte de los operarios (p. ej. el aprendizaje es más completo porque el trabajador aprecia una mayor diversidad de actividades que en una planta de gran dimensión, y tiene mayor conciencia de los principios físicos y mecánicos de las tareas que realiza), y por otro, suelen ser más intensivas en mano de obra.

El nivel de ahorro local. Representa un indicador del nivel de riqueza que disponen los individuos de una comunidad para instalar o expandir una firma. Naturalmente, cuanto mayor sea el ahorro, mayores son las posibilidades de financiar la inversión. A su vez, un elevado nivel de ahorro es reflejo de un alto nivel de ingreso, y por ende, de demandas más diversificadas, que pueden constituir la base de explotación de nichos de demanda (Verheul et al., 2001).

El funcionamiento del mercado de capitales. El rol del financiamiento en la concreción de proyectos de inversión ha sido enfatizado por

${ }^{10} \mathrm{Al}$ principio se suponía que a mayor nivel educativo alcanzado, mayores son las chances para que el individuo pueda concretar un proyecto de negocios en términos del acceso al conocimiento, ya que la educación superior ofrece más herramientas de evaluación que las instancias de formación anteriores. Sin embargo, el nivel educativo alcanzado también aumenta las perspectivas de ingreso como asalariado y puede disminuir el atractivo de la actividad independiente. 
numerosos trabajos (Evans \& Leighton, 1989; Blanchflower \& Oswald, 1998, entre otros). Las estrategias de segmentación de la oferta de fondos por parte de bancos e instituciones de crédito, por ejemplo, están orientadas a disminuir el riesgo de la cartera de deudores. Ello encarece el crédito para las nuevas firmas o las de menor tamaño, debido a que la probabilidad de fracaso es mayor con relación a las empresas establecidas o de gran dimensión. En este sentido, el funcionamiento del mercado de capitales -en términos de grado de concentración de la oferta y reglas de fijación de precios (interés)- resulta relevante a la hora de evaluar los determinantes de la empresarialidad.

\subsubsection{Factores sectoriales y macroeconómicos}

Este ítem se refiere, básicamente, a la cantidad y calidad de las oportunidades que brinda el ambiente para el despliegue de las actividades emprendedoras, y suele contener dos grandes grupos de elementos. Por un lado, aquellos de carácter sectorial, esto es, los específicos a cada rama (estudiados generalmente en el ámbito de la organización industrial), y por otro, los que dependen de variables macroeconómicas. A continuación se ofrece un breve panorama de cada uno.

En la especificación de los factores sectoriales se deben distinguir aquellos que influyen en la entrada de firmas de los que afectan a la supervivencia y/o expansión. El concepto de "atractividad neta” puede ser útil para identificar a los primeros. En este término se resumen, para un sector dado, los beneficios esperados de instalar una nueva firma corregidos por los respectivos costos de puesta en marcha. Varios autores señalan que en particular, la tasa de rentabilidad del sector y el crecimiento de la demanda aumentan las expectativas de ganancia de las firmas potenciales, y por ende, estimulan la entrada. Por su parte, la existencia de economías de escala, las prácticas de diferenciación de producto intensivas en recursos (I+D o publicidad), la magnitud de los costos hundidos requeridos y las eventuales diferencias en los niveles de la curva de costos entre las firmas potenciales y las establecidas aumentan los costos de entrada a un sector dado, y por ende, la des- alientan ${ }^{11}$. Los empresarios reciben de este modo señales acerca de las oportunidades de beneficio que ofrece la estructura económica. De aquí se infiere la relevancia que adquiere la composición sectorial de una economía, en la medida en que define la disponibilidad de oportunidades atractivas de negocio con que se encuentran los empresarios.

La supervivencia y crecimiento de las firmas, por su parte, están apoyadas en general en las capacidades creativas de las organizaciones. Las capacidades requeridas, sin embargo, varían de un sector a otro; en algunos sólo basta con los saberes acumulados por el empresario y/o los trabajadores, y en otros estos activos no son suficientes como punto de apoyo de un proceso sostenido de expansión. Existen por lo menos dos enfoques modernos a partir de los cuales se interpretan las diferencias intersectoriales observadas en la evolución de las empresas.

Por un lado, la noción de "regímenes tecnológicos" distingue los sectores donde la innovación (como oportunidad de crecimiento) es concretada principalmente por firmas jóvenes, y por ende, pequeñas ("régimen entrepreneurial"). En ese tipo de ambientes las firmas ya establecidas no pueden consolidar una ventaja duradera basada en el control de una base de conocimientos de su propiedad. Por este motivo, se ven permanentemente desafiadas por la llegada de innovadores ajenos a la actividad. En otros ambientes, las mejoras tecnológicas se gestan en forma planificada en laboratorios de I+D (asociados, en general, a firmas de gran tamaño), conformando lo que se denomina un "régimen rutinizado". Allí, la mayor parte de las oportunidades de progreso basadas en la innovación es acaparada por las organizaciones de larga trayectoria en la actividad y que han recorrido un proceso histórico de acumulación de conocimiento, sobre cuya base construyeron sus ventajas competitivas.

Por otro lado, la hipótesis del ciclo de vida de la industria (Gort \& Klepper, 1982; Klepper, 1996) postula que las condiciones tecnológicas y de mercado de

${ }^{11}$ Estos elementos serán analizados con más detalle en el último ítem de este apartado. De todos modos, para quienes estén interesados en profundizar las cuestiones relativas a los determinantes sectoriales de la natalidad de firmas, se recomienda la revisión de Geroski (1991). 
un sector se modifican a lo largo de su evolución temporal. Así, en las etapas “juveniles” existen perspectivas favorables para la entrada de nuevas firmas innovativas. Mientras que en fases posteriores, cuando las técnicas productivas y las características del producto se han consolidado, los emprendedores potenciales encuentran dificultades para ingresar $y / o$ para competir en un pie de igualdad con las organizaciones ya establecidas, que son precisamente las que ostentan el control de las claves tecnológicas del negocio. El período que ofrece más perspectivas de crecimiento para las firmas (aunque también más riesgoso) es aquel donde aún la eficiencia o los precios no son críticos para competir, debido a que todavía no ha surgido un diseño dominante en la industria. En esta etapa es posible ingresar al mercado ofreciendo distintas variedades de las existentes, incluso con algún grado de ineficiencia. A medida que la actividad se consolida, las características del producto comienzan a definirse de un modo más preciso, y la capacidad de las empresas para expandirse pasa a depender de elementos relacionados con los costos. Esto genera un proceso de salida masiva de la actividad (shake $o u t$ ), que refuerza la ventaja de las sobrevivientes para introducir innovaciones $y$, por ende, progresar.

El argumento que pretende volcarse aquí es el siguiente. Por un lado, es sabido que las actividades industriales difieren de un modo sistemático en términos de las tecnologías y las formas de competencia. Por otro, ambos factores inciden sobre el grado de receptividad del ambiente de mercado para la experimentación empresarial (oportunidades de negocios, perspectivas de crecimiento empresarial, etc.). Así, se infiere que -al igual que las condiciones de entrada- la composición sectorial de la economía se erige en un factor de peso respecto de la intensidad y naturaleza de la actividad empresarial.

Además de los factores sectoriales, varios trabajos señalan que la existencia de un ambiente propicio para la actividad empresarial se ve fuertemente influida por aspectos macroeconómicos y de la política económica, que a su vez pueden manifestarse en las rentabilidades sectoriales. Existen varios mecanismos a través de los cuales las variables macroeconómicas podrían incidir sobre la empresarialidad. Por ejemplo, el comportamiento del sistema de precios afecta el nivel de incertidumbre sobre la evolución futura de la economía, y por ende, la capacidad de los agentes para planificar sus acciones (Pindyck \& Solimano,
1993). En el plano fiscal-administrativo, por su parte, frecuentemente se sostiene que los costos de concretar un proyecto de inversión aumentan con el nivel de complejidad de las distintas instancias burocráticas de la administración pública y disminuye con el grado de coordinación de un organismo a otro (Brunetti et al., 1997; OCDE, 1998a). En otros aspectos, en cambio, hay menos consenso; la política comercial, la orientación del Estado (p. ej. desregulación y privatización), el funcionamiento del mercado de trabajo (p. ej. flexibilidad de la duración de la jornada laboral y de las remuneraciones) y del mercado de capitales (p. ej. liberalización) forman parte de las discusiones más recientes sobre el impacto de la política económica en el dinamismo empresarial $^{12}$.

\subsection{Determinantes no triviales: las instituciones}

Como se mencionó anteriormente, la rama keynesiana del desarrollo prestaba atención a los factores de demanda, esto es, a los modos de aumentar las oportunidades de beneficio y su percepción en el sector privado, especialmente en las economías periféricas. En general, los trabajos identificaban factores sectoriales y macroeconómicos como los argumentos principales de las oportunidades de beneficio. Sin embargo, una cuestión adicional, que ha recibido mayor atención desde principios de los ' 80 , es que los incentivos de demanda pueden verse potenciados o atenuados ante determinadas circunstancias que están fuera del alcance del propio sector industrial o la coyuntura macroeconómica. Como se detalla anteriormente, aspiraciones diferentes de la búsqueda de beneficio o restricciones de acceso a los recursos constituyen elementos que pueden demorar la reacción de los agentes a dichos incentivos. La identificación de los factores que impulsan o retardan la respuesta de los individuos a las oportunidades de beneficio constituye el fundamento del estudio de la empresarialidad.

${ }^{12}$ MacDonald (1994), Bassanini et al. (2001) y Kusum Das (2002) abordan distintos aspectos del ambiente regulatorio y su impacto sobre la productividad. En todos los trabajos se registra una postura favorable a las políticas pro-competitivas (apertura, privatización, desregulación). Rodrik (1992), Stiglitz (1999), Gore (2000) y Easterly (2001) cuestionan la validez empírica de una relación positiva entre la aplicación de este tipo de políticas y el aumento de la productividad a nivel agregado en los PMD. 
Tradicionalmente, la investigación sobre los determinantes de la empresarialidad se centraba casi exclusivamente en cuestiones microeconómicas, como los intereses personales de los empresarios y sus capacidades adquiridas e innatas. No obstante, aun cuando las cualidades de los individuos representan una porción significativa en la explicación del perfil empresarial de un país o región, muchos autores (Gerschenkron, 1953; Young, 1971; Etzioni, 1987) han señalado que estos factores están moldeados por las características de la organización social y política de un determinado territorio.

Los elementos que subyacen fuera de la esfera económica y no se limitan al individuo son calificados en la literatura como "institucionales". El estudio de los factores institucionales (esencialmente su definición y elementos constitutivos) y su rol en las distintas facetas del proceso de desarrollo forma parte del interés central de la economía de las instituciones. Los trabajos de Veblen y Commons constituyen el punto de partida de las principales nociones conceptuales en la temática. Posteriormente Ayres (1957), Olson (1965; 1996), Williamson (1985), North (1990) y David (1994) marcaron nuevos hitos en la literatura institucionalista ${ }^{13}$.

3.2.1. Los costos de transacción y el rol de las instituciones

Las distintas corrientes de pensamiento involucradas en el estudio de las instituciones tienen su origen en la crítica a tres supuestos centrales de la teoría neoclásica: el de racionalidad, el de información completa y el de independencia de las preferencias individuales (Dupuy et al., 1994). Brevemente, el levantamiento de estos supuestos implica el reconocimiento de que los agentes enfrentan costos para conocer la calidad, precios y confiabilidad de las transacciones con otros agentes y que las decisiones microeconómicas pueden recibir influencias exteriores, que se combinan con sus voluntades individuales.

El enfoque institucionalista reconoce que toda transacción incurre en la necesidad de: (a) obtener y verificar la información acerca de la calidad y cantidad de los bienes y servicios a intercambiar, la repu-

${ }^{13}$ Los artículos de Hodgson $(1993 ; 1998)$ y Samuels (1995) ofrecen un panorama bastante completo de los avances en este campo de reciente expansión. tación y antecedentes de la contraparte de la transacción y la calidad de los derechos de propiedad que se están intercambiando; (b) diseñar, monitorear y reafirmar el contrato de transferencia; y (c) prever la ocurrencia de litigios y resolución de disputas. Los costos asociados a estas tareas son conocidos como "costos de transacción" (CT).

Los CT aluden a los costos de especificar lo que se está intercambiando y de reafirmar los acuerdos, y derivan precisamente de los límites en la capacidad de interpretación de los individuos, de la existencia de asimetrías de información y de la posibilidad de conductas oportunistas. Estas restricciones (internas y externas al individuo) implican costos tanto en el proceso de toma de decisiones como en la implementación de las mismas, y por ende, la posibilidad de suspender acuerdos entre agentes. Así, cuanto mayores sean los CT, más obstáculos encuentra la coordinación espontánea de los individuos, esto es, la posibilidad de celebrar intercambios de un modo sistemático y auto-organizado ${ }^{14}$.

La reducción de los CT implícitos en las transacciones se consigue a través de una serie de restricciones sobre el comportamiento. Estas restricciones, conocidas también como instituciones, representan un conjunto de procedimientos designados para detectar desvíos y reforzar el cumplimiento de los acuerdos. Estas normas reducen entonces los costos de aplicación de determinadas acciones (p. ej. obtención de información o previsión de posibles fraudes) destinadas a disminuir la incertidumbre. De este modo, la función de las instituciones es proporcionar una estructura a las decisiones cotidianas que "señala" a los agentes qué comportamiento es preferido, requerido o prohibido (Favereau, 1989). El contrato exige una reglamentación, un derecho contractual no modificable por los particulares, y este tiene un origen social. Para que el acto de intercambio se haga efectivo se debe despejar la desconfianza

\footnotetext{
${ }^{14}$ La base teórica de los costos de transacción descansa en los problemas de agente-principal derivados de la existencia de información asimétrica. Brevemente, la presencia de asimetrías de información incentiva a que alguna de las partes de la transacción (la que posee mayor información) no cumpla -parcial o totalmente- con sus obligaciones sin que las otras puedan notarlo. En la literatura, estas situaciones pueden derivar en fenómenos de selección adversa, riesgo moral y mercados incompletos. Varian (1990) ofrece una exposición detallada de estas cuestiones.
} 
y la sospecha. Cualquier duda sobre la objetividad (p. ej. incertidumbre acerca de la calidad del producto) desnaturaliza profundamente el marco del intercambio hasta bloquear incluso la transacción (Akerlof, 1970; Stiglitz, 1987).

En suma, las instituciones representan mecanismos externos a la mente humana que, simultáneamente con los "modelos mentales" individuales, son utilizados para procesar la información que proviene del entorno (North, 1990). Estos mecanismos están compuestos por normas y códigos que informan a los agentes acerca de su posición y las consecuencias de sus acciones (Feeny, 1988). Con todo, las instituciones que prevalecen en la práctica, aunque dan lugar a intercambios que no se realizarían en su ausencia, no consiguen eliminar totalmente los $\mathrm{CT}$, y a veces pueden agregar distorsiones a los mercados (Nelson \& Sampat, 2000). Por lo tanto, el nivel que finalmente alcancen los $\mathrm{CT}$ es variable. Su magnitud depende de la tecnología disponible para transferir y evaluar información y de la calidad de las instituciones (p. ej. transparencia y eficacia de las reglas y grado en que éstas reducen los costos de recolección de información).

\subsubsection{Tipos de instituciones}

Las instituciones tienen componentes formales e informales. Los primeros comprenden el conjunto de leyes y reglamentos escritos diseñados para delimitar (en términos legales) el comportamiento de los individuos. Los elementos informales aluden a las convenciones y símbolos no escritos, compartidos por una sociedad en torno a ciertos valores y sanciones hacia la conducta individual y colectiva. En general, las instituciones informales están asociadas con la cultura y costumbres de una comunidad (Olson, 1996) ${ }^{15}$. Por su parte, la proliferación de reglas escritas está estrechamente relacionada con el grado de especialización y división del trabajo (o grado de desarrollo) del sistema económico (Burky \& Perry, 1998)

\subsubsection{Instituciones formales y empresarialidad}

La distinción anterior resulta útil para comprender el modo en que instituciones y empresarialidad están vinculadas. Es posible plantear dos mecanismos por los cuales las instituciones pueden influir sobre el dinamismo empresarial de un territorio dado. Por un lado, el nivel de complejidad de las normas escritas (estabilidad y coherencia de las políticas, transparencia en su implementación, número de instancias burocráticas de aplicación, demora relativa de resoluciones, etc.) puede acentuar o mermar las oportunidades de beneficio percibidas por los agentes. En este sentido, si bien se admite que las instituciones reducen la incertidumbre implícita en las transacciones, ciertas configuraciones -en términos de leyes y reglamentos- pueden provocar un aumento de los CT, específicamente cuando el costo de conocer las regulaciones es muy elevado. En estos casos, la cantidad o complejidad de los procedimientos escritos puede demorar o suspender ciertas transacciones (p. ej. tiempo que insume la habilitación de ciertas actividades comerciales, tiempo consumido para conocer reglamentaciones relativas a algunas operatorias específicas como importación o exportación, etc.) (Brunetti et al., 1997). Por este motivo, la debilidad institucional de un país o región en su faceta formal puede originarse en la escasez de normativas que dan lugar a un elevado grado de incertidumbre, $o$ alternativamente, en la multiplicidad y superposición de normas que encarecen la reducción de la incertidumbre.

\footnotetext{
${ }^{15}$ Se debe aclarar, no obstante, que autores como Nelson y Sampat (2000) o Verheul et al. (2001) señalan que los elementos de carácter cultural y las cuestiones legales no deberían ser incluidos en un mismo plano de análisis. En primer lugar, la consideración del cuerpo de leyes y estructuras organizacionales, junto con el sistema de creencias y procesos políticos de una sociedad, puede convertir al término instituciones en un recipiente de difícil tratamiento en un análisis coherente. La cobertura de un campo conceptual tan vasto puede resultar demasiado compleja para su tratamiento teórico, aunque en la práctica operen simultáneamente. Segundo, se argumenta que no siempre instituciones formales y cultura son consistentes. En algunos casos, como sugiere North (1990), las reglas escritas emergen naturalmente de las convenciones informales, aunque esto no siempre se cumple. Esto dificulta aún más cualquier definición conceptual y la identificación de relaciones de correlación. En tercer lugar, desde el punto de vista metodológico, la cultura no es observable mientras que las leyes y procedimientos formales sí lo son. Este matiz ha dado lugar a una extensa ramificación en la economía de las instituciones, que podría ser distinguida, en términos generales, por el énfasis otorgado a uno u otro componente. Las diversas posturas se encuentran presentadas en forma exhaustiva en Samuels (1995).
} 


\subsubsection{Instituciones informales y empresarialidad}

El cuestionamiento que el enfoque institucionalista hace a la teoría neoclásica acerca del supuesto de independencia de las preferencias individuales se basa en el reconocimiento de que los objetivos y actitudes de los agentes se forman en un sistema de valores, tradiciones y convenciones no escritas que prevalecen en la comunidad. Este segundo canal mediante el cual las instituciones pueden influir sobre la conducta de los agentes, y a su vez sobre el desarrollo económico, fue sugerido inicialmente por Max Weber al proponer una relación causal entre la reforma protestante y la emergencia del capitalismo occidental durante el siglo XVI. Así como Weber visualizaba a las convicciones religiosas como el principal elemento que regulaba el sistema de valores en los siglos XV y XVI, varios autores enfocados al mismo análisis para el siglo XX, han asignado esta función a la familia y al sistema educativo (Kasdan, 1971). En conjunto, esta serie de trabajos analiza la empresarialidad desde una perspectiva esencialmente sociológica. Baumol (1990) ha sido tal vez el principal difusor contemporáneo de la idea de que son las creencias y la valoración social de ciertas actividades las que moldean la aparición y consolidación de un sector social dispuesto y capacitado a ejercer el rol de burguesía.

El análisis sociológico de la empresarialidad considera a la creación y gestión de una firma como un fenómeno esencialmente grupal. El empresario es visto como miembro de una comunidad. Esta comunidad puede intervenir directamente en el proyecto (ofreciendo apoyo financiero, clientes, contactos, etc.) o indirectamente, a través de convenciones establecidas sobre ciertas prácticas y valoración social de la actividad independiente. Este tipo de explicaciones se basa, en la mayoría de los casos, en experiencias particulares (norte de Italia, Países Bajos, etc.), analizando los grupos sociales e ideologías dominantes que lideraron procesos de industrialización y desarrollo local. No obstante-como se mencionó anteriormente-, si bien se reportan diferencias sustanciales de un caso a otro en estos aspectos, el denominador común a estas interpretaciones parece ser la hipótesis de que las valoraciones que la comunidad de referencia hace de la actividad independiente, así como su receptividad cultural y apertura mental, inciden significativamente en la aparición y consoli- dación de un grupo emprendedor. Se deriva entonces que cuanto más apreciada sea la actividad empresarial en una comunidad, mayor será la motivación de los individuos para convertirse en empresarios. Esto es apoyado a su vez por otra serie de elementos, como el sistema de estratificación social, los canales de movilidad y las ideologías dominantes (Papanek, 1962; Hagen, 1971; Shapero \& Sokol, 1982; Wennekers \& Thurik, 1999).

Esta hipótesis se basa en el supuesto de que la organización de la sociedad experimenta un alto grado de integración, condición para que la asimilación de estos valores ocurra de un modo natural. Existe un enfoque alternativo que postula precisamente lo opuesto; la insatisfacción o falta de integración del individuo a las formas de organización social imperantes pueden favorecer la empresarialidad (Bates, 1993). El argumento se basa en la "hipótesis de la marginación", del "desplazamiento" o del "empuje", que destaca la relevancia de un evento "negativo" como impulsor de la creación de firmas. Brevemente, para esta aproximación la decisión individual de auto-emplearse no siempre es "voluntaria"; el desempleo o la migración colocan frecuentemente a los individuos en posiciones marginales respecto de la comunidad en la medida en que implican su participación en el mercado laboral informal, de bajo salario o de empleo temporal. Esta circunstancia, según esta hipótesis alternativa, puede provocar una sensación de insatisfacción y estimular la búsqueda de actividades que permitan escapar de dicha situación ${ }^{16}$.

Por otro lado, como se ha definido más arriba, la empresarialidad no se limita al análisis de los factores que inciden en la decisión de ser empleado o patrón por parte de los individuos, sino también a la conducta misma de las empresas, una vez establecidas.

\footnotetext{
${ }^{16}$ El enfoque de la marginación difiere con el resto de las explicaciones sociológicas de la empresarialidad, que centran sus argumentos en torno al significado que la sociedad otorga a la actividad empresarial. Lo que parece intervenir para este enfoque es, en cambio, la escasa remuneración del empleo asalariado y la alta segmentación en el mercado de trabajo, lo que en conjunto, hace más atractivo el empleo autónomo. Por este motivo, la hipótesis de la marginación no se contrapone a que la sociedad valore positivamente la actividad independiente. En todo caso, lo que parece enfrentarlas es el supuesto sobre la posición del individuo en la jerarquía social.
} 
Si bien en estos términos la empresarialidad parece tener límites más ambiguos (p. ej. existen muchos puntos de vista acerca de qué conductas pueden ser consideradas "emprendedoras" y cuáles caen fuera de este rango), basta con asociar empresarialidad con el dinamismo que exhiben las firmas. Un elemento que parece ocupar un papel central en esta dimensión es la existencia de vínculos fluidos entre las empresas y entre éstas y el resto de las organizaciones del sistema. Pero la emergencia de relaciones (de colaboración e incluso de mercado) inter-firma e interorganizacionales también tiene un componente social. En este sentido, si se supone que los patrones de interacción son relevantes tanto para el desempeño de las firmas individuales como para el conjunto del sistema productivo, el análisis no puede reducirse entonces a la simple adición de las conductas individuales. Así, las convenciones a través de las cuales la población moldea sus intereses se impregnan también en el modo en que sus organizaciones interactúan.

En particular, la existencia de lazos de confianza y el rol que ocupa la reputación personal en una comunidad constituyen, según Lazonick (2001), la base social de cualquier transacción (mediada o no por un acuerdo de precios). El argumento es que ambos elementos representan indicadores adecuados del grado de reafirmación de los acuerdos (esto es, un alto costo de incumplimiento o de fraude en la relación) y esto disminuye los CT para quienes participan en los intercambios. En contraposición, un ambiente caracterizado por la falta de confianza puede conducir a las firmas a dedicar tiempo y dinero para protegerse del comportamiento oportunista de aquellos con los que tiene un vínculo. Esto puede desestimular algunas iniciativas empresariales, especialmente las que requieren de un alto compromiso de otros agentes (OCDE, 1998a).

En suma, mientras que las reglas formales afectan a la capacidad de los individuos para reunir e interpretar la información, las informales moldean sus aspiraciones. Por este motivo, se considera que una comprensión más integral del fenómeno de la empresarialidad no debe limitarse a los factores concentrados en los rasgos individuales de los empresarios actuales y potenciales, sino que debe tener en cuenta además la configuración institucional en la cual dichos rasgos se engendran. Asimismo, el hecho de que los aspectos individuales y colectivos reflejen procesos profundamente interrelacionados invalida cualquier intento de identificar el peso de cada una en el dinamismo empresarial.

\subsection{La circularidad de los determinantes de la empresarialidad}

El conjunto de determinantes de la empresarialidad enumerado más arriba puede ser abordado a través de una categorización alternativa compuesta a su vez por dos grupos de factores. Por un lado, se considera que la empresarialidad depende de las oportunidades de inversión que la economía genera (conocidas como factores de "atracción" o "arrastre"). En general, estas fuerzas inductoras están vinculadas con elementos estructurales y transitorios que aumentan la atractividad de un sector de producción. Se deriva entonces que cuanto más "generosa" sea la economía, tanto en el agregado como en el interior de sus sectores productivos, más oportunidades tiene la actividad empresarial de cristalizar sus proyectos. En este sentido, se entiende que tanto las variables sectoriales y macroeconómicas como el conjunto de reglamentaciones escritas forman parte de los factores de arrastre, al reflejar las oportunidades de inversión en la economía percibidas por los agentes.

Por otro lado, algunos autores señalan que la economía en su conjunto no podría superar nunca una fase de estancamiento o recesión si no fuera por la emergencia de proyectos empresariales que, aun en dicho contexto, se formulan y concretan. En este sentido, la empresarialidad no dependería entonces de las señales macro y sectoriales, sino de la propia calidad y cantidad de los proyectos de inversión permanentemente generados por los emprendedores. En esta visión, el ambiente sólo funciona como soporte de un conjunto de capacidades y aspiraciones de un grupo de empresarios que "presionan" sobre el desarrollo económico. Al conjunto de elementos que conforman esta esfera se los conoce como factores de "empuje". Las cuestiones referidas a la personalidad de los empresarios, a sus capacidades o incluso al sistema de valores y creencias de una comunidad, forman parte de este segundo grupo.

No obstante, si bien es fácil comprender la existencia de ambas fuerzas (de atracción y de presión), 
el análisis en esta materia no ha conseguido avanzar significativamente más allá de esta distinción. Ello se debe, en primer lugar, a que algunos de los factores de inducción parecen operar simultáneamente como elementos de empuje. Por otra parte, en uno y otro canal subyacen elementos no observables que ponen trabas a la refutación de la teoría o a su contrastación con la evidencia empírica. Por este motivo, cada uno de los elementos arriba enumerados debe ser entendido como un determinante de la empresarialidad desde una perspectiva estática. En términos dinámicos, conviene tener presente la circularidad latente entre factores de arrastre y de empuje y el efecto simultáneo que algunas variables ejercen sobre ambos. Ello implica que en el terreno empírico, es difícil precisar si la empresarialidad en algunos territorios es fuerte (débil) por abundancia (escasez) de oportunidades o por exceso (déficit) de agentes capaces y motivados.

\section{La relación entre empresarialidad y territorio}

Para quienes se encuentran vinculados al análisis regional, la empresarialidad no resulta un tópico secundario. Al formar parte de lo que se conoce como el "lado de la oferta", la posibilidad de que este atributo se presente en forma no homogénea en el espacio representa, para los investigadores, una nueva fuente de explicación de las diferencias interregionales de desarrollo ${ }^{17}$. Progresivamente se ha ido

\footnotetext{
${ }^{17} \mathrm{Si}$ bien las conexiones entre empresarialidad y desarrollo fueron exploradas en varias oportunidades (Leibenstein, 1968; Kilby, 1971; o desde una perspectiva neo-marxista, Baran, 1952 y Frank, 1973), las implicancias derivadas de los modelos de crecimiento endógeno de Romer (1990) y Lucas (1988) otorgaron un nuevo impulso a su tratamiento. En esencia, estos modelos incorporan el supuesto de rendimientos crecientes en la producción derivados de derrames provenientes del capital humano. Esta variable estaría representada tanto por el nivel de conocimientos y habilidades de los asalariados como por las capacidades y aspiraciones de los capitalistas. Algunas estimaciones indican que estos componentes -considerados en forma conjunta- podrían tener un impacto sobre el crecimiento del producto de mayor magnitud que la acumulación de capital o la expansión del empleo. Como la dinámica de estos modelos admite la posibilidad de divergencia en los niveles de ingreso per cápita, la empresarialidad podría ser considerada una nueva fuente de diferenciación en el desempeño económico entre países y regiones.
}

generalizando la idea de que las consideraciones sobre esta materia resultan esenciales en todo análisis coherente y completo del cambio regional. Algunos autores sugieren incluso que un tratamiento extensivo de la empresarialidad podría constituir la base microeconómica del cambio estructural a nivel regional (Sweeney, 1987; Suárez Villa, 1989).

La razón para referir la empresarialidad a la esfera regional se basa en que una parte de sus determinantes tiene un alcance geográfico limitado. Por ejemplo, si la empresarialidad es evaluada en términos del nacimiento de nuevas empresas, la posibilidad de colocar inicialmente la producción en el mercado local adquiere gran importancia, ya que la demanda potencial inmediata de la nueva organización es en su mayor parte local. A su vez, en la medida en que la producción añadida por las empresas de reciente creación se destine al mercado local, los rasgos de la estructura manufacturera que determinan la entrada, supervivencia y crecimiento de las firmas son también los del ámbito regional. Por ende, los factores sectoriales y coyunturales expuestos anteriormente son esencialmente de carácter regional (excepto aquellos referidos a la evolución de variables macroeconómicas), al menos durante las primeras etapas de vida de las firmas.

Más allá de la espacialidad con que se manifiestan algunos determinantes específicos de la creación de empresas, como la demanda o la estructura industrial, diversos trabajos implícitamente reflejan que otros determinantes de la empresarialidad, podrían diferenciarse también en el territorio. A continuación, un breve comentario de ellos.

\subsection{La espacialidad de las convenciones sociales}

Hasta aquí se mostró que el análisis de la empresarialidad puede adquirir una dimensión regional si se considera el carácter localizado de algunos de sus determinantes, como los incentivos de demanda, las características de la estructura productiva o el acceso a los recursos. Estos elementos fueron considerados anteriormente como parte de las condiciones básicas para influir sobre el perfil empresarial de los individuos. Se ha especulado acerca de la posibilidad de que algunos de los determinantes no triviales de la empresarialidad tuvieran además un carácter espacialmente limitado. En la 
medida en que estas reflexiones ganen una mayor adhesión en las discusiones, la empresarialidad podría ser considerada como un fenómeno esencialmente regional ${ }^{18}$. En la literatura, la dimensión institucional con mayor raigambre regional se apoya en las instituciones informales. El argumento es sencillo: en tanto la emergencia de convenciones, tradiciones y sistemas de valores sociales requieren de contactos personales y experiencias comunes, su generalización enfrenta fuertes barreras espaciales.

Como notan Maskell y Malmberg (1995), las disposiciones de carácter formal enfrentan menos obstáculos para ser copiadas de una región a otra. Sin embargo, los condicionantes culturales subyacentes (e incluso algunos relacionados con las habilidades productivas) requieren largos períodos de tiempo para ser asimilados. Esto hace que los procesos tanto de cambio como de consolidación institucional sean naturalmente lentos, acumulativos y por ende, intransferibles de un territorio a otro. En este sentido, la empresarialidad se concibe como un fenómeno con fuerte continuidad temporal y discontinuidad espacial.

Más aun, varios autores consideran que la cooperación entre los agentes proviene de una modalidad común de asimilar situaciones, problemas y oportunidades. Por ende, si dicha modalidad difiere de un territorio a otro, la empresarialidad diferirá espacialmente. Esto, por su parte, alienta posibles explicaciones de las diferencias en su nivel de desarrollo económico.

Es preciso mencionar que la hipótesis de que las instituciones informales son en sus fases constitutivas de naturaleza territorial proviene esencialmente del plano empírico. La adhesión que ganó entre algunos investigadores se explica básicamente por la proliferación de estudios de caso en torno a algunas experiencias de industrialización reciente o de dinamización del tejido productivo, localizadas en países desarrollados. El patrón de desarrollo de cada una de estas regiones refleja, según sus analistas, una

\footnotetext{
${ }^{18}$ Los autores que adhieren a esta hipótesis reconocen que no todos los determinantes del dinamismo empresarial se circunscriben exclusivamente a la escala netamente local, y pueden abarcar conjuntamente a varias regiones; sin embargo, su homogeneidad disminuye cuanto mayor es el área geográfica considerada (Suárez Villa, 1986; 1989).
}

base institucional conformada por rasgos culturales y de organización social que difieren de un caso a otro.

Por ejemplo, la industrialización del NE de Italia durante los '50 y'60 se caracterizó por el liderazgo de una pequeña burguesía formada por campesinos emigrados del agro, con marcados lazos filiales y mandatos religiosos en la formación de redes de contención social, y un fuerte compromiso de los gobiernos locales en la articulación de los requerimientos del mercado con las habilidades de los agentes (Becattini, 1978; 1987). Esta experiencia contrasta con la observada en algunas regiones de Francia (Ile de France, Ródano-Alpes y Provenza). Storper (1997) relata que las principales aglomeraciones industriales francesas (especializadas en actividades de alta tecnología) evidencian estándares tecnológicos relativamente dinámicos respecto de la frontera internacional. Este dinamismo se apoya en pronunciadas jerarquías organizacionales. Los actores que forman parte de la élite (consejeros tecnológicos del Estado, diseñadores, etc.) definen las convenciones centrales del mercado (calidad, precio, diseño, materiales, etc.) hacia toda la cadena de producción (filière). En cambio, los clusters industriales norteamericanos emergentes durante los ' 60 y '70 surgieron, según Saxenian (1994), como resultado del desprendimiento (spin off) de profesionales de los equipos de investigación de las universidades y de firmas en sectores relacionados. El marco institucional que parece haber estado subyacente en este proceso es un sistema de incentivos orientado a premiar la generación de novedades rentables. Como resultado de ello, se registra una elevada propensión por parte de los trabajadores calificados a generar conocimientos aplicados en ciertas áreas (especialmente electrónica e informática) y capitalizar estas ventajas mediante la creación de una nueva firma.

El repaso de estas experiencias deja la impresión de una marcada diferenciación regional en términos de la configuración institucional vigente, que a su vez se plasma en diferentes estilos de desarrollo. Las lecciones extraídas de estos estudios de caso con frecuencia han sido utilizadas como un argumento favorable a la idea de que no existe un único vector de condiciones iniciales que conduzca al éxito. Sin embargo, esta hipótesis entraña el riesgo de considerar 
que cualquier vector de condiciones iniciales derive en patrones virtuosos de desarrollo.

\subsection{La espacialidad de las organizaciones que impulsan la empresarialidad}

En los análisis regionales se ha puesto recientemente bajo consideración la posibilidad de que el empresario se vea impedido de asumir completamente las funciones que tradicionalmente se le atribuyen (percepción de oportunidades, innovación, gestión). Como se explicó anteriormente, en ausencia de limitaciones motivacionales, el ejercicio de este amplio rango de funciones por parte de los empresarios individuales puede verse obstaculizado por restricciones de acceso a los recursos. Para algunos autores, estas barreras pueden ser atenuadas por la actuación de un conjunto de organizaciones interrelacionadas que transmitan los medios (informativos, financieros, etc.) necesarios para concretar las funciones propias de la empresarialidad (Suárez Villa, 1986; Sweeney, 1987; Lazonick, 1991; 2001). Dentro de esta categoría se incluye a las cámaras de comercio, agrupaciones empresarias sectoriales, sindicatos, clubes, entes de apoyo a emprendimientos productivos, centros de investigación y transferencia tecnológica, talleres de formación profesional, etc. Los mecanismos específicos por los cuales estas entidades pueden incrementar la calidad y cantidad de proyectos empresariales son de dos tipos: por un lado, las organizaciones pueden disminuir los costos asociados con una determinada tarea empresarial (en cuyo caso, operarían como condiciones básicas, agrupadas anteriormente en el inciso $2.1^{19}$ ). Por otro lado, pueden actuar como agentes catalizadores de experiencias y actitudes lubricando el proceso de generación de expectativas, preferencias y convenciones (Storper, 1997). El derrame de recursos que este tipo de entidades (universidades, laboratorios, cámaras empresarias, firmas de

\footnotetext{
${ }^{19}$ En los últimos años, algunos investigadores en este tópico han centrado su atención en el rol de las gremiales empresarias. Estas asociaciones pueden desarrollar una extensa gama de actividades, que en uno u otro sentido, intentan aumentar el dinamismo empresarial del área; entre ellas, la recolección de información y construcción de bases de datos, la gestión de compras conjuntas, el dictado y promoción de talleres de capacitación y actualización empresarial, la organización de ferias y encuentros de negocios y la coordinación y gestión de créditos bancarios de sus asociados (Sweeney, 1987; Schmitz, 1999b; Meyer-Stamer, 1999).
}

servicios especializados, etc.) es capaz de generar tendría, en principio, un alcance geográficamente limitado (Jaffe et al., 1993; Audretsch \& Feldman, 1996).

Bajo el supuesto de que el grado de complejidad organizacional de estos entes está positivamente asociado con la cantidad, calidad y densidad de enlaces entre los agentes del sistema, el estudio de su funcionamiento puede constituir un modo de abordar las manifestaciones empíricas de la cooperación. De modo que la empresarialidad, a nivel regional y en términos de las conductas de los agentes, podría ser estudiada tanto desde el análisis de los modos de vinculación predominantes como desde la observación del funcionamiento de sus organizaciones intermedias.

En suma, la percepción de oportunidades, generación de innovaciones y mejoras de eficiencia son tareas asignadas generalmente a la firma, pero en los casos en que alguno de estos roles (especialmente la innovación) no pueda ser enteramente cumplido por la empresa en forma autónoma, los nuevos enfoques atribuyen al territorio un papel especial.

\subsection{Las politicas locales de fomento a la empresarialidad}

Otro de los motivos que ha justificado la concepción de la empresarialidad como un fenómeno regional, más allá del carácter localizado de las instituciones informales y el alcance espacialmente limitado de la actuación de las organizaciones intermedias, es el renovado rol asignado a las autoridades locales en la revitalización de las regiones (Schmitz, 1999a). Como se anticipó anteriormente, esta creciente consideración está relacionada con la progresiva descentralización de las funciones del Estado, especialmente las que generalmente son calificadas como "políticas activas". Este proceso, que comenzó en Europa a fines de los '70, se difundió en Estados Unidos durante los ' 80 y continuó en América Latina en los '90, convierte a los municipios y/o autoridades regionales en depositarios de algunas de las herramientas de promoción industrial y regional. Varios documentos de la OCDE (1998a; 1998b; 1999) enfatizan que los programas de autoempleo, asistencia a las pequeñas empresas y fomento de la innovación son mejor conducidos por 
los gobiernos locales ${ }^{20}$. Los argumentos que justifican la descentralización de las funciones del Estado, en la cual se enmarca la transferencia de las políticas de apoyo al sector productivo, se basan en consideraciones de eficiencia (conocimiento más ajustado de las necesidades de la población por parte de los gobiernos locales, mayor capacidad de control de las burocracias por parte de los individuos) y de participación política (mayor democratización de las decisiones públicas) ${ }^{21}$.

Según lo expuesto hasta aquí, el origen del carácter territorial de la empresarialidad sería claro: a las eventuales diferencias espaciales que surjan en las condiciones básicas que impulsan el dinamismo empresarial se agregan las de carácter institucional. Tanto la idiosincrasia y cultura local como las organizaciones intermedias y las políticas locales de difusión de la "cultura empresarial" evidencian la presencia subyacente de las instituciones como fuente de diferencias regionales ${ }^{22}$. Amin y Thrift (1993) resumen este conjunto de relaciones en la noción de "densidad institucional", que se compone básicamente del conjunto de organizaciones de la región, del nivel de interacción que adop$\tan$ y de los acuerdos socialmente definidos. En conjunto, estos elementos otorgan legitimidad a las conductas y prácticas locales, reafirman las relaciones de confianza, y por ende, estimulan la empresarialidad. En definitiva, consolidan el carácter "embebido" de la actividad industrial.

Hasta este punto parece haber bastante consenso entre autores de diversas corrientes de pensamiento en que empresarialidad y sus bases institucionales

\footnotetext{
${ }^{20}$ Incubadoras de empresas, servicios de información y consultoría, programas de entrenamiento y de capacitación empresarial pueden ser algunos elementos de las iniciativas locales.

${ }^{21}$ Finot (2001) ofrece una revisión de los fundamentos teóricos de la descentralización.

${ }^{22}$ Conviene tener presente, sin embargo, la observación de los revisores de este trabajo notando que el carácter "territorial" de las instituciones no necesariamente equivale a un alcance local o regional. En algunos casos, lo territorial puede circunscribirse a lo local, mientras que en otros abarca a varios países. El alcance de lo territorial dependerá, entonces, del caso a evaluar.
}

son elementos estrechamente relacionados en el análisis del desarrollo regional para un momento del tiempo dado. Evidencia de ello se encuentra al observar territorios donde la acumulación de capital y la emergencia de organizaciones modernas de la producción encuentran enormes trabas, mientras que en otros espacios, estos fenómenos parecen concomitantes naturales del progreso social en general (Hoselitz, 1957; 1960; Helliwell \& Putnam, 1995). Sin embargo, la conceptualización del problema en estos términos desde una perspectiva dinámica conlleva algunas limitaciones. Si bien las condiciones de mercado y las de orden institucional-especialmente las que involucran a la cultura y tradiciones de la comunidad- pueden resultar consistentes entre sí en un período determinado, es probable que ello ocurra de un modo contingente (Amin \& Thrift, 1993). Es más, aun cuando resulten compatibles en alguna de las distintas fases de su evolución, no hay garantía de que esta situación se sostenga en la fase siguiente. El argumento que sostiene esta hipótesis es la relativa inercia que exhiben las instituciones durante largos períodos, en contraste con la mayor frecuencia de los cambios en el ambiente económico. Por ejemplo, Glasmeier (1992), Cooke y Morgan (1992) ${ }^{23}$ y Guerrieri y Iammarino (2001) refieren las experiencias de la industria del reloj en Suiza y de algunos distritos italianos y alemanes, que actualmente están enfrentando problemas de ajuste en sus instituciones, ya sea para introducir cambios o bien para mantener ciertas convenciones locales a medida que se insertan en redes internacionales de producción y distribución. Lo notorio en estos informes es que se trata de casos que en períodos anteriores fueron considerados paradigmáticos en términos de desarrollo industrial localizado. Estos ejemplos muestran que el resultado de la interacción entre el mercado y las instituciones no está determinado por ninguna ley general, y por ende, no puede ser anticipado (Maskell \& Malmberg, 1995).

El siguiente gráfico ilustra en forma esquemática las explicaciones del desarrollo económico basadas en la empresarialidad, eje central de la exposición de este apartado.

\footnotetext{
${ }^{23}$ Ambos citados por Amin y Thrift (1993).
} 
Figura 1. Empresarialidad y desarrollo económico.

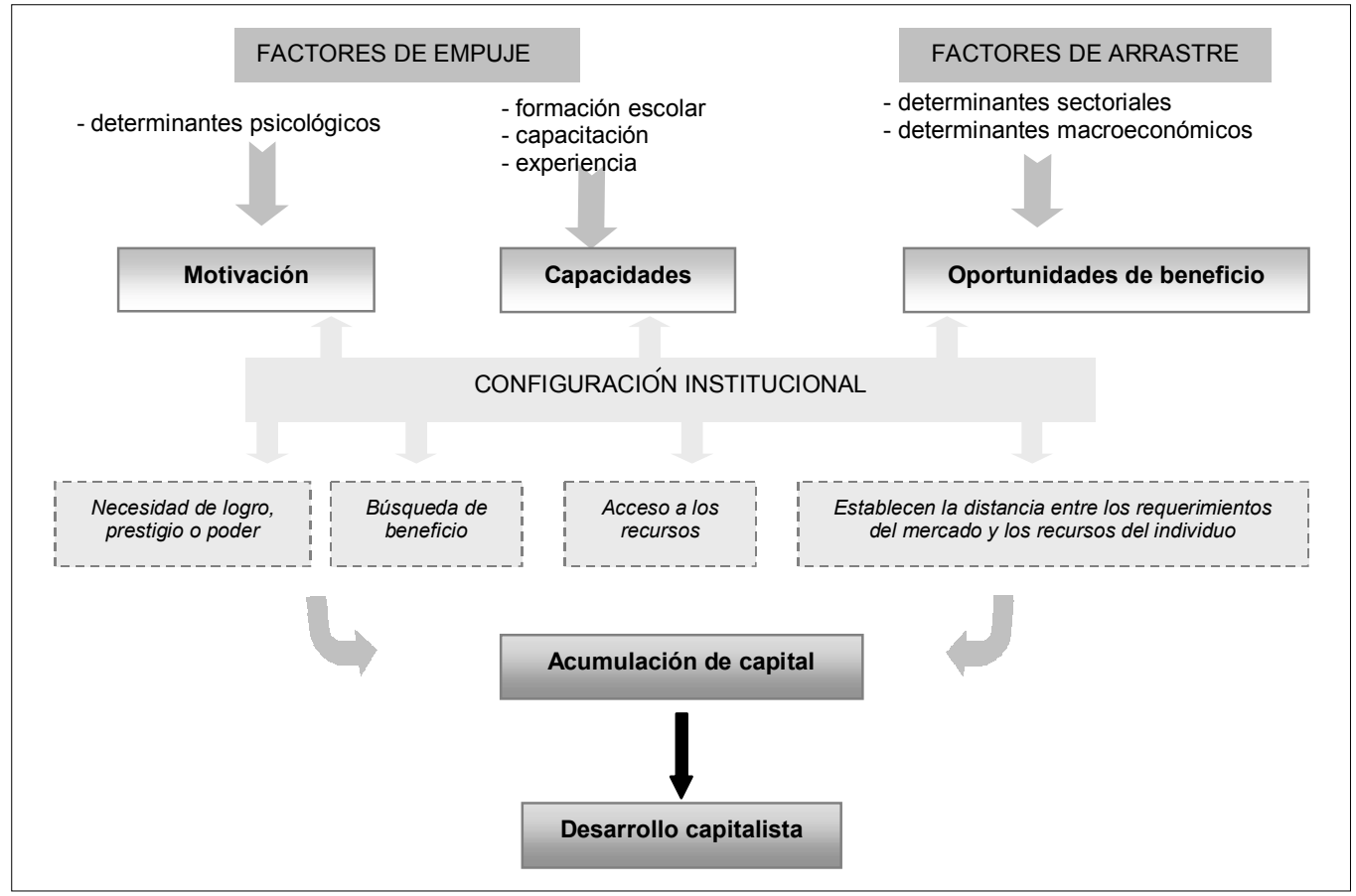

Fuente: elaboración propia.

\section{Síntesis}

La teoría general del desarrollo y la ciencia regional han incorporado recientemente en sus esquemas analíticos consideraciones sobre empresarialidad e instituciones, áreas de notable progreso en la disciplina económica. La mayor atención que reciben estos aspectos se fundamenta en el nuevo rol del Estado frente a la promoción del desarrollo económico de regiones y países, con un carácter menos activo que el que tomó durante las décadas de 1950 y 1960. Este menor protagonismo del sector público en las trayectorias de crecimiento económico acrecentó la importancia del sector privado, en especial del segmento empresarial. Esto justificó entonces la incorporación en la economía del desarrollo de elementos que contemplaran las motivaciones, capacidades y limitaciones exógenas de los empresarios. Pero el propio avance del análisis impuso la necesidad de encontrar explicaciones más profundas de las dotaciones empresariales de naciones y de regiones; los límites eventuales de los empresarios para sobrevivir y crecer no pueden tener una base individual, especialmente cuando el "(sub)desarrollo empresarial” alcanza a una gran proporción de la economía en su conjunto. Es por ello que junto con el enfoque de la empresarialidad aparece además la necesidad de incorporar también elementos de la economía institucional en el análisis del desarrollo general y local.

En el plano empírico, estos progresos han sido incorporados con diversas metodologías, que van desde la consideración de factores históricos, sociológicos y culturales de carácter mesoeconómico hasta estudios microeconómicos que analizan los rasgos empresariales e institucionales de un sistema económico dado. Por este motivo, es aún incipiente cualquier evaluación acerca de la eficacia de estos elementos en los trabajos empíricos. Naturalmente, futuras líneas de investigación deberán asumir con el tiempo un gran esfuerzo metodológico, que sin duda permite anticipar resultados promisorios. 


\section{Referencias bibliográficas}

Akerlof, G. (1970). “The market for 'lemons': quality uncertainty and the market mechanism". Qua J $E c, 84:$ 488-500.

Alburquerque, F. (1999). Desarrollo, redes e innovación. Lecciones sobre desarrollo endógeno. Madrid: Pirámide.

Alstrom, S. (1998). "The dynamics of the firm". $43^{\text {rd }}$ World Conference of ISCB, Singapore.

Amin, A. \& N. Thrift (1993). "Globalization, institutional thickness and local prospects". Revue d'Economie Regionale et Urbaine, 3: 405-430.

Audretsch D. B. \& M. P. Feldman (1996). "R\&D spillovers and the geography of innovation and production". Am Ec Rev, 86, 3: 630-640.

Audretsch, D. B., J. Weigand y C. Weigand (2002). "The impact of the SBIR on creating entrepreneurial behavior". Ec Dev Qua, 16,1: 32-38.

Ayres, C. (1957). "Institutional economics: discussion”. Am Ec Rev Pap \& Pro, 47: 26-27.

Baran, P. (1952). "On the political economy of backwardness". Manchester School of Economics and Social Studies, 20: 66-84.

Bassanini, A., S. Scarpetta y P. Hemmings (2001). "Economic growth: the role of policies and institutions. Panel data evidence from OECD countries". OECD Economics Department Working Papers \# 283.

Bates, T. (1993). "Theories of entrepreneurship". Bingham, R. D. \& R. Mier (eds.), Theories of local economic development. Newsbury Park CA: Sage, 248-264.

Baumol, W. (1968). "Entrepreneurship in economic theory”. Am Ec Rev Pap \& Pro; 58, 2: 64-71.

(1990). "Entrepreneurship: productive, unproductive and destructive". Am Ec Rev, 98, 3: 893-921.

Becattini, G. (1978). "The development of light industry in Tuscany: An interpretation". Economic Notes, 2-3: 107-23.

(ed.) (1987). Mercato e forze locali: Il Distretto Industriale. Bologna: Il Mulino.

Bhide, A. (1996). "The questions every entrepreneur must answer". Har Bus Rev, 120130.

Binks, M. \& C. Ennew (1997). "Growing firms and the credit constraint". Sma Bus Ec, 8: 1725.
Blanchflower, D. \& A. Oswald (1998). "What makes and entrepreneur? Evidence on inheritance and capital constraints". J Lab Ec, $16,1: 26-60$.

Brunetti, A., G. Kisunko y B. Weder (1997). "Institutional obstacles for doing business". World Bank Policy Research Working Paper \# 1759.

Burky, S. \& G. Perry (1998). Beyond the Washington' Consensus: Institutions matter. Washington DC: The World Bank.

David, P. (1994). "Why are institutions the 'carriers' of history? Path dependence and the evolution of conventions, organizations and institutions". Str Ch\& Ec Dyn, 5, 2: 205-220.

Dupuy, J.-P., F. Eymard-Duvernay, O. Favereau, A. Orlean, R. Salais y L. Thévenot (1994). "Introducción a la economía de las convenciones". Eymard-Duvernay, F. (ed), Economía de las convenciones. Buenos Aires: Asociación Trabajo y Sociedad.

Easterbrook, W. (1949). "The climate of enterprise”. Am Ec Rev Pap \& Pro, 39, 3: 322335.

Easterly W. (2001). “The lost decades: Developing countries stagnation in spite of policy reform 1980-1998". JEc Gro; 6, 2: 135-157.

Etzioni, A. (1987). "Entrepreneurship, adaptation and legitimation: A macro-behavioural perspective”. J Ec Beh \& Org, 8: 175-189.

Evans, D. \& L. Leighton (1989). "Some empirical aspects of entrepreneurship”. Am $E c \operatorname{Rev}, 79$, 3; 519-535.

Favereau, O. (1989). "Marchés internes, marchés externes". Revue économique, 40, 2:273-328.

Feeny, D. (1988). "The demand for and supply of institutional arrangements". Ostrom, V., D. Feeney y H. Picht (eds.), Rethinking institutional analysis and development. Issues, alternatives and choices. International Center for Economic Growth. California: Library of Congress Cataloging-in-Publication Data, pp. 159-209.

Finot, I. (2001). "Descentralización en América Latina: teoría y práctica”. ILPES Serie Gestión Pública \# 12.

Florence, P. S. (1953). The logic of British and American industry. London: Routledge \& Kegan.

(1964). Economics and sociology of industry. London: C.A. Watts \& Co. 
Frank, G. (1973). "La dependencia ha muerto. Viva la dependencia y la lucha de clases". Des $E c, 13$, 49.

Freeman, K. (1976). "The significance of Mc Clelland's achievement variable in the aggregate production function". Ec Dev \& Cul Ch, 24, 4: 815-824.

Garnsey, E. (1988). "Who is an entrepreneur is the wrong question". Am J Sma Bus, 12: 11-32.

(1996). "A new theory of the growth of the firm". 41 $1^{\text {st }}$ World Conference of ISCB, Stockholm.

Geroski, P. A. (1991). Market dynamics and entry. Oxford, UK-Cambridge, MA: Basil Blackwell.

Gerschenkron, A. (1953). "Social attitudes, entrepreneurship and economic development". Explorations in Entrepreneurial History, 6: 1-19.

Gore, C. (2000). "The rise and the fall of Washington Consensus as a paradigm for developing countries". World Development, 28, 5.

Gort, M. \& S. Klepper (1982). "Time paths in the diffusion of product innovations". $E_{c} J, 92$ : 630-653.

Granovetter, M. (1985). "Economic action and social structure: The problem of embeddedness". Am J Soc, 91: 481-510.

Greenfield, S. \& A. Strickon (1981). "A new paradigm for the study of entrepreneurship and social change". Ec Dev \& Cul Ch, 9, 3: 467499.

Greenwald, B. \& J. Stiglitz (1990). "Asymmetric information and the new theory of the firm: financial contsraints and risk behavior". $A m E c$ Rev, 80, 2: 160-165.

Greiner, L. (1974) "Evolution and revolution as organizations grow”. Har Bus Rev, July-Aug: $37-46$.

Guerrieri, P. \& S. Iammarino (1999). “The dynamics of Italian industrial districts: towards a renewal of competitiveness?" Guerrieri, P., S Iammarino y C. Pietrobelli (eds.), SME clusters in globalised industry: Italy and Taiwan. London: Edward Elgar Aldershot.

Hagen, E. (1971). "How economic growth begins: A theory of social change". Kilby, P. (ed.), Entrepreneurship and economic development. $\mathrm{New}$ York: The Free Press.

Harbison, F. (1956). "Entrepreneurial organization as a factor in economic development". Qua JEc;

\section{0, 3: 364-379.}

Helliwell, J. F. \& R. D. Putnam (1995). "Social capital and economic growth in Italy". Eas Ec J, 21, 3: 295-307.

Hirschman, A. (1958). La estrategia del desarrollo económico. Buenos Aires: Fondo de Cultura Económica.

(1970). Exit, voice and loyalty. Cambridge, MA: Harvard Univ Press.

Hodgson, G. (1993). Economía y evolución. Madrid: Colegio de Economistas de Madrid-Celeste Ediciones.

(1998). "The approach of institutional economics". JEc Lit, 36: 166-192.

Hoselitz, B. (1957). "Non economic factors in economic development". Am Ec Rev Pap \& Pro, 47: 28-41.

(1960). Sociological aspects of economic growth. Glencoe: The Free Press.

ILO Development-and-Technical-CooperationDepartment (1995). Gender, poverty and employment: Turning capabilities into entitlements. Geneva: GO.

Jaffe, A., M. Trajtenberg y R. Henderson (1993). "Geographic localization of knowledge spillovers as evidenced by patent citations". Qua $J E c, 108:$ 576-598.

Kasdan, L. (1971). "Family structure, migration and the entrepreneur". Kilby, P. (ed.) Entrepreneurship and economic development. New York: The Free Press.

Kilby, P. (ed.) (1971). Entrepreneurship and economic development. New York: The Free Press.

Kirzner, I. (1973). Competition and entrepreneurship. Chicago: The University of Chicago Press.

Klepper, S. (1996). "Entry, exit and growth and innovation over the industry life cycle". Am Ec $\operatorname{Rev}, 86,3: 562-583$.

Knight, F. (1921). Risk, uncertainty and profit. Iowa: The Library of Economics and Liberty.

Kunkel, J. (1963). "Psycological factors in the analysis of economic development". J Soc Iss, 99, 1: 68-87.

(1971). "Values and behaviour in economic development”. Kilby, P. (ed.) Entrepreneurship and economic development. New York: The Free Press.

Kusum Das, D. (2002). "Trade liberalisation and industrial productivity: an assessment of developing countries experiences". Working Paper 
\# 77. Indian Council for Research on International Economic Relations, april.

Langlois, R. \& N. Foss (1999). "Capabilities and organization: The rebirth of production in the theory of economic organization”. Kyklos, 52, 201-18.

Langlois, R. (1998). "Capabilities and the theory of the firm”. Foss, N. \& B. Loasby (eds.), Economic organization, capabilities and co-ordination: Essays in honour of G. B. Richardson. London: Routledge.

Lazonick, W. (1991). Business organization and the myth of the market economy. Cambrigde, MA: Cambridge University Press. (2001). "The theory of innovative enterprise”. INSEAD Working Paper, Project The European Commission DGXII \# 053.

Leff, N. (1979). "Entrepreneurship and economic development: The problem revisited". JEc Lit, 17:46-64.

Leibenstein, H. (1966). "Allocative efficiency vs. 'XEfficiency'”, Am Ec Rev, 56: 392-415.

(1968). "Entrepreneurship and development”. Am Ec Rev Pap \& Pro, 58, 2: 72 83.

Lucas, R. (1988). "On the mechanics of economic development". JMon Ec, 22: 3-42.

MacDonald, J. M. (1994). "Does import competition force efficient production?”. Rev Ec \& Sta, 76, 4: 721-727.

Malicia, E. \& E. Feser (1999). Understanding local economic development. New Brunswick, NY: Center for Urban Policy Research.

Maskell, P. (1999). "Social capital and regional development”. NordRegio WP\# 51999.

Maskell, P. \& A. Malmberg (1995); "Localised Learning and industrial competitiveness"; $R e$ gional Studies European Conference on "Regional Futures"; Gothenburg; 6-9 May.

Meyer-Stamer, J. (1999). "What can Business Associations do to stimulate Local and Regional Economic Development? Experience from Santa Catarina, Brazil". International Institute for Labour Studies/ILO Caribbean Office Regional Workshop Decent Work and Global Competition: New Roles for Enterprises and their Organizations, Port of Spain, 20-22 October.
Nelson, R. \& B. Sampat (2000). "Making sense of institutions as a factor shaping economic performance".J Ec Beh \& Org, 44: 31-54.

Nelson, R. \& S. Winter (1982). An evolutionary theory of economic change. Cambridge, MA: Harvard University Press.

Nelson, R. (1991). "Why do firms differ and how does it matter?" Str Man J, 12: 61-74.

North, D. (1990). Instituciones, cambio institucionaly desempeño económico. Buenos Aires: Fondo de Cultura Económica.

OCDE (1998a). Fostering entrepreneurship. Paris: OECD Publications.

(1998b). Local management for more effective employment policies. Geneva: OECD Publications.

(1999). Decentralizing employment policies. New trends and challenges. OECD Proceedings: The Venice Conference.

O'Kean, J. M. (2000). La teoría económica de la función empresarial: el mercado de empresarios. Madrid: Alianza.

Olson, M. (1965). "The logic of collective action". Cambridge, MA: Harvard University Press. (1996). "Big bills left on the sidewalk: why some nations are rich, and others poor".J Ec Per; 10, 2: 3-24.

Papanek, G. (1962). "The development of entrepreneurship". Am Ec Rev, 52, 2: 46-58.

Pindyck, R. \& A. Solimano (1993). "Economic instability and aggregate investment". NBER Working Paper \# 4380.

Rodrik, D. (1992). "The limits of trade policy reform in developing countries". J Ec Per, 6, 1: 87-105.

Romer, P. (1990). "Endogenous technical change". JPolEc, 98, 5: 71-101.

Samuels, J. (1995). "The present state of institutional economics". Cam JEc, 19: 569590.

Saxenian, A. (1994). Regional advantage: Culture and competition in Silicon Valley and Route 128. Massachusetts: Harvard University Press.

Schmitz, H. (1999a). "Collective efficiency and increasing returns". Cam JEc, 23, 4.

(1999b). "From ascribed to earned trust in exporting clusters". J Int $E c, 48,1$.

Schumpeter, J. (1912). The theory of economic development. Cambridge, Mass: Harvard University Press. 
(1942). Capitalism, socialism and democracy. New York: Harper.

Shapero, A. \& L. Sokol (1982). "The social dimensions of entrepreneurship". Kent, C., D. Sexton y K. Vesper (eds.), The encyclopedia of entrepreneurship. Englewood Cliffe, NJ: Prentice Hall, pp. 72-90.

Singh Laumas, P. (1962). "Schumpeter's theory of economic development and underdeveloped countries". Qua JEc, 76: 653-659.

Soltow, J. (1968). "The entrepreneur in economic history”. Am Ec Rev, 58: 84-92.

Stiglitz, J. (1987). "The causes and consequences of dependence of quality of price". J Ec Lit, 25: 1-18.

(1999). "Whither reform? Ten years of transition". Annual Bank Conference on Development Economics, World Bank; apr.

Storey, D. (1994a). Understanding the small business sector. London: Routledge.

(1994b). "New firm growth and banking financing". Sma Bus Ec, 6: 139-150.

Storper, M. (1997). The Regional World: Territorial development in a global economy. New York: The Guilford Press.

Suárez Villa, L. (1986). "El empresario: factor estratégico en las transformaciones territoriales", Estudios Territoriales, 20.

(1989). The evolution of regional economies: Entrepreneurship and macroeconomic change. New York: Praeger Publishers.

Subbarao, K., J. Braithwaite y J. Jalan (1995). "Protecting the poor during adjustment and transitions". World Bank Human Capital WP\# 16233.

Sweeney, G. (1987). Innovation, entrepreneurs and regional development. London: Frances Pinter.

Teece, D. \& G. Pisano (1994). "The dynamic capabilities of firms: an introduction". Ind \& Cor Cha, 3, 3: 537-556.

Tekiner, A. (1980). "Need achievement and international differences in income growth: 1950-1960". Ec Dev \& Cul Ch, 28, 2: 293320.

Varian, H. (1990). Microeconomía intermedia. Un enfoque moderno. Barcelona: Antoni Bosch.

Verheul, I., S. Wennekers, D. Audretsch y R. Thurik (2001). "An eclectic theory of entrepreneurship: policies, institutions and culture". EIM Research Report H0012/E, Zoetermeer, Mar.

Wennekers, S. \& R. Thurik (1999). "Linking entrepreneurship and economic growth". Sma Bus Ec, 13, 1:27-55.

Williamson, O. (1985). The economic institutions of capitalism: Firms, markets, relational contracting. London: Macmillan.

Young, F. (1971). "A macrosocial interpretation of entrepreneurship". Kilby, P. (ed), Entrepreneurship and economic development. New York: The Free Press. 